\title{
Mobile Online Courses for the Illiterate: The eVideo Approach
}

\author{
Yasmin Patzer $^{1(\bowtie)}$, Johanna Lambertz ${ }^{2}$, Björn Schulz ${ }^{2}$, and Niels Pinkwart ${ }^{1}$ \\ 1 Humboldt-University Berlin, Unter den Linden 6, 10099 Berlin, Germany \\ patzer@informatik.hu-berlin.de \\ https://cses.informatik.hu-berlin.de/en/ \\ 2 Arbeit und Leben Berlin-Brandenburg (DGB/VHS), \\ Kapweg 4, 13405 Berlin, Germany \\ http://www.berlin. arbeitundleben.de
}

\begin{abstract}
More than half of Germany's functional illiterates are gainfully employed adults. This paper presents the eVideo approach that aims at people with poor basic education. The course "eVideo mobile - digital media in hospitality industry" is a game-based work-related eLearning course. It is based on an inclusive eLearning platform. Basic educational skills are addressed in workplace-related interactive videos and exercises on different competency levels. In a small pilot study users were observed while using the course and afterwards questioned in interviews.
\end{abstract}

Keywords: Mobile learning · Inclusive eLearning

Functional illitracy $\cdot$ Poor basic education

There are about 7.5 million functional illiterates in Germany [1]. More than half of them are gainfully employed adults. Therefore offers for this target group should deal with content, which is workspace related. There are already different existing national and international projects like [2-4] that are addressing this topic. The eVideo approach [5] is aiming at this as well, with gamebased work-related eLearning courses that are targeting basic educational skills, including literacy and numeracy as well as media literacy. There is already some research on eLearning and inclusion [6] as well as on game-based training in basic education [7]. In the eVideo course the user interacts with colleagues in short video sequences, completes typical work tasks and thereby solves an underlying work-related adventure. The core idea of this format is a combination of realistic workplace-related videos and exercises on different competency levels. The course of events is guided and linear and also designed for "technical novices". Nevertheless some users might need additional support.

The novelty presented in this paper is a redesign of the eVideo technology so that the educational approach is retained while the system runs on a smartphone, thereby enabling time and space independent access. This redesign has been implemented in the context of the course "eVideo mobile - digital media in hospitality industry". The course is developed to be responsive and can be used

(C) The Author(s) 2018

K. Miesenberger and G. Kouroupetroglou (Eds.): ICCHP 2018, LNCS 10896, pp. 379-383, 2018.

https://doi.org/10.1007/978-3-319-94277-3_59 
on both tablets and desktop computers, but follows a mobile first approach. Previous eVideo courses were developed for desktop computer usage only.

The development of the mobile eVideo system followed a design science research paradigm. Contrary to former eVideo courses, the new version is technically based on the LAYA platform - an inclusive eLearning platform [8]. Structure and design of the course should allow recognition for users, who already know other eVideos. For a target group with mostly low media literacy level, this eases orientation and navigation between the courses. The challenging aspect of this combination was to bring together an existing inclusive eLearning platform, with the eVideo course concept and script (that were not designed with inclusion in mind) and then make all that usable on smartphones and accessible for users with low media literacy levels. UI design and content had to be adapted to the small screen size, without a loss of the course characteristics. A challenging point was the adaptation of the exercises with their three difficulty levels. The highest level was the most challenging, as it is not only more difficult to solve, but also contains more text than level one and two. In iterative cycles, content and layout of each exercise were designed and tested. This also required the replacement of exercise types that were unsuitable for the target users on a small screen. For instance, one exercise that was planned as drag and drop of text elements from an email was changed into a marking exercise. Otherwise the exercise would have been overloaded and confusing. Exercise types that are used in this course are single- and multiple choice, clozes, drag and drop and marking exercises.

Universal Design for Learning (UDL) has been taken into account for the development of this course. There are different levels of support for users, which address different levels of poor literacy skills on the one hand and different types of learners on the other. For instance, all videos have subtitles and all texts in the course have an additional audio alternative (see Fig. 1: loud speaker icons on the left). There is also a dictionary available that includes all potentially difficult vocabulary and technical terms used in the exercises. Besides, motivating feedback and a help function are part of each exercise and the icons used throughout the course are consistent.

The Screenshot in Fig. 1 shows exercise 3. Below the progress bar is the "Anleitung" button, which opens the instruction text for the exercise. The instruction for each exercise is read out automatically the moment it is opened. Below the instruction button, there are three more buttons: the left button (icon: magnifier) opens information that is needed to solve the exercise, the middle one (icon: question mark) is a help button and the right one (icon: book) leads to the dictionary. For this exercise, the button with the magnifier icon has the text "Phishingmerkmale" (engl. phishing characteristics) and opens a list of typical characteristics of phishing mails. After having read and/or heard those the user is asked to mark three typical characteristics of phishing mails for the easiest level. For the other two complexity levels, the e-mail is more difficult and five (level 2) or seven (level 3) characteristics have to be marked. After solving the exercise, the users get immediate feedback on their performance. If they made 


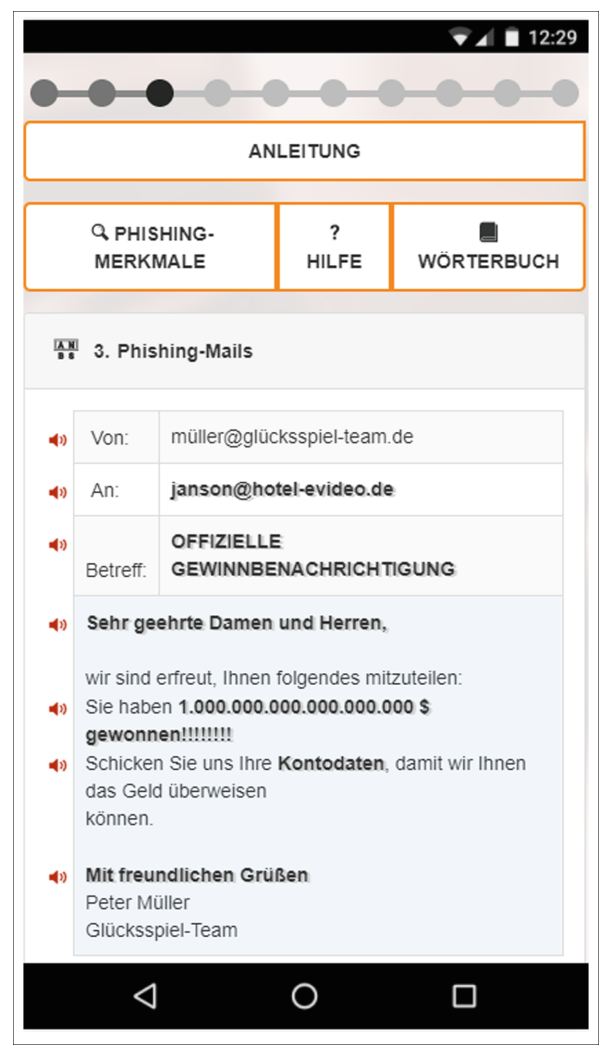

Fig. 1. Screenshot exercise 3

mistakes, they get exercise specific hints. After three failed trials, the correct solution is shown and the user can continue with the course.

Motivation plays an important role for this user group as many people with poor basic education have made negative experiences connected to learning. This is addressed by a novel gamification and adaptation concept, which adapts known principles like collecting badges and trophies or recommending changes in difficulty for an inclusive user group.

A small pilot study has been conducted with nine users, who were observed while using the system for at least $50 \mathrm{~min}$. Afterwards, the users were interviewed about their experience. A problem-centered guided interview was chosen, as it allows a strong focus on users' perceptions and opinions. Users were asked about computer and smartphone usage, eLearning and gamification experiences. Five users had poor basic education, the other four had no impairments. This set of participants was chosen, to make sure that the needs and requirements of the main target group of the eVideo courses were met on the one hand. And on the other hand, experts for technical development and design were asked to give their opinion on the redesigned course. All participants liked the idea, content and structure of the course and pointed out that they could easily identify with 
the person addressed in the interactive videos. Especially the participants with poor basic education liked the combination of text and audio in the videos as well as in the exercises. Yet, some of the users without impairments thought it rather distracting, that the audio automatically started, as they were opening and reading an instruction text. Furthermore the feedback after each exercise was perceived as motivating and encouraging no matter if the exercise was solved correctly in the first trial or not.

The users' feedback in the pilot study lead to adaptations in the course. For instance the functionality of the audio buttons was changed, to allow pausing the audios. Furthermore some instructions were changed according to the feedback.

The course can be a starting point to address poor basic education problems of employees in the hospitality industry. It should be embedded in a blendedlearning context to have the best possible effect. The novel mobile version allows users to work on the course on their own and independent of location (i.e., possibly also at work). In a next step studies with more heterogeneous users are necessary to ensure, that the course is as inclusive as it aims to be. Afterwards larger empirical studies with the course and a publicly accessible version are planned in order to investigate the system effects under real conditions.

\section{References}

1. Grotlüschen, A., Riekmann, W., Buddeberg, K.: Hauptergebnisse der leo. - LevelOne Studie. In: Grotlüschen, A., Riekmann, W. (eds.) Funktionaler Analphabetismus in Deutschland - Ergebnisse der ersten leo. - Level-One Studie, pp. 15-53. Waxmann, Münster, New York, München, Berlin (2012)

2. lit.voc - Literacy and vocation (n.d.): European Workplace Literacy Profile (European Core Curriculum). http://www.grundbildung-und-beruf.info/et_dynamic/ page_files/637_datei.pdf?1383242976. Accessed 24 Mar 2018

3. NDS: Tasmanian Disability Sector Language, Literacy and Numeracy Skills Action Plan 2016-2017 (2016). https://www.nds.org.au/the-workplace-literacyproject. Accessed 24 Mar 2018

4. Klinkhammer, D., Schubarth, B., Schwarz, S., Spranger, T.M., Ungerer, J.: Wie wirkt Grundbildung im Betrieb? - Erste Ergebnisse einer Studie zur Kompetenzentwicklung. In: Sozialverband VdK Deutschland e.V. (ed.) Sozialrecht+Praxis, Vol. 9/17 (2017)

5. Schulz, B., Lambertz, J.: eVideo - ein digitales Lernangebot zur arbeitsplatzbezogenen Verbesserung von Grundkompetenzen. Wege der Erreichung einer lernungewohnten Zielgruppe. In: Magazin Erwachsenenbildung.at, vol. 30. Wien (2017)

6. Patzer, Y., Sell, J., Pinkwart, N.: Anforderungen und ein Rahmenkonzept für inklusive E-Learning Software. In: Lucke, U., Schwill, A., Zender, R. (eds.) GI Lecture Notes in Informatics - Tagungsband der 14. e-Learning Fachtagung Informatik (DeLFI), pp. 257-268. Bonn, Köllen Druck+Verlag GmbH (2016)

7. Malo, S., Neudorf, M., Wist, T.: Game-based Training in der Alphabetisierung. Entwicklung eines Lernspiels für die Grundbildung. MedienPädagogik: Zeitschrift für Theorie und Praxis der Medienbildung, vol. 15, pp. 1-15 (2009)

8. Patzer, Y., Pinkwart, N.: Inclusive E-Learning - towards an integrated system design. In: Cudd, P., De Witte, L. (eds.) Studies in Health Technology and Informatics, vol. 24. IOS Press (2017) 
Open Access This chapter is licensed under the terms of the Creative Commons Attribution 4.0 International License (http://creativecommons.org/licenses/by/4.0/), which permits use, sharing, adaptation, distribution and reproduction in any medium or format, as long as you give appropriate credit to the original author(s) and the source, provide a link to the Creative Commons license and indicate if changes were made.

The images or other third party material in this chapter are included in the chapter's Creative Commons license, unless indicated otherwise in a credit line to the material. If material is not included in the chapter's Creative Commons license and your intended use is not permitted by statutory regulation or exceeds the permitted use, you will need to obtain permission directly from the copyright holder.

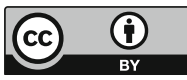

